\section{Does FreezePruf Topical Spray Increase Plant Resistance to Freezing Stress?}

\author{
Jeff A. Anderson ${ }^{1}$
}

\begin{abstract}
ADDITIONAL INDEX WORDs. bermudagrass, cockscomb, cryoprotection, freeze avoidance, freeze tolerance, pepper, supercooling, tomato

SUMMARY. One method of plant freeze protection involves the application of compounds that promote freeze avoidance or tolerance. FreezePruf, a commercially available product recently marketed to improve both freeze avoidance and tolerance, contains polyethylene glycol, potassium silicate, glycerol, silicone polyether surfactant, and a bicyclic oxazolidine antidessicant. The goal of the present study was to evaluate the protection level provided by FreezePruf using laboratory-based methods involving plants and plant parts from species capable and incapable of lowtemperature acclimation. FreezePruf did not lower the freezing temperature of pepper (Capsicum annumm) seedlings, celosia (Celosia argentea) seedlings, detached tomato (Solanum lycopersicum) leaves, or postharvest tomato fruit. Spray application of the putative cryoprotectant did not increase the freeze tolerance of bermudagrass (Cynodon dactylon) crowns or stolons. It is possible that a greater level of protection could be achieved with other species or different experimental protocols.
\end{abstract}

$\mathrm{P}$ lant resistance to freezing stress includes avoidance, evasion, and tolerance strategies (Levitt, 1980). Many annual plants complete the vegetative phase of the life cycle when freezing temperatures do not normally occur, effectively evading the stress. Other annuals are exposed to temperatures capable of triggering the phase transition of water from liquid to solid, but avoid freezing through supercooling and colligative effects of solutes. Perennial plants that persist in colder climates can acclimate to tolerate extracellular ice formation. Some perennial plants exhibit mixed modes of protection with most cells undergoing equilibrium extracellular freezing, but with groups of cells or organs deep supercooling (Kuwabara et al., 2011).

Freezing temperature depression in freeze-avoiding plants is accomplished primarily through supercooling, with melting point depression from solutes being secondary. The extent of supercooling varies with plant weight (Ashworth and Davis,

Department of Horticulture and Landscape Architecture, Oklahoma State University, Stillwater, OK 74074

Use of the Controlled Environment Research Laboratory is appreciated. Research was supported by the Oklahoma Agricultural Experiment Station.

Approved for publication by the Director, Oklahoma Agricultural Experiment Station. Mention of a trademark, proprietary product, or vendor does not constitute a guarantee or warranty of the product and does not imply its approval to the exclusion of other products or vendors that also may be suitable.

${ }^{1}$ Corresponding author. E-mail: jeff.anderson@okstate. edu.
1984), cooling rate and duration (Yelonosky, 1983), and properties of ice nucleators. The templates for ice formation can be intrinsic to the plant tissues (Proebsting and Gross, 1988) or from bacterial (Lindow, 1983) or fungal origin (Pouleur et al., 1992). Ice nucleators function by lining up supercooled water molecules into a structure resembling ice. A close lattice fit and large template size favors nucleation at warmer temperatures. Tissue hydration and presence of surface moisture can also affect freezing temperature (Cary and Mayland, 1970; Gusta et al., 2009), but the mechanisms are not completely understood.

In contrast with tender plants that must avoid freezing to survive, many plant species have the capacity to acclimate and tolerate extracellular freezing. Acclimation to freezing temperatures has been studied extensively and significant advances in methodology have led to greater understanding of several low-temperature signal transduction pathways. The best characterized system is the COR regulon, which contains hundreds of genes under the control of CBF (C-repeat) transcription factors (Stockinger, 2009). COR proteins and products of additional low temperature-induced pathways act directly or indirectly to increase freeze tolerance. It appears that plants must clear a number of mechanistic hurdles to survive progressively lower temperatures, with many of the injury mechanisms focusing on membrane systems (Minami et al., 2009).

In spite of recent advances in elucidation of acclimation pathways and factors affecting ice nucleation, freeze injury continues to be a significant problem both in private landscapes and production agriculture. Therefore, there is considerable interest in improving plant resistance to low temperatures or modifying microclimates to reduce stress severity. Breeding programs have incrementally improved freeze tolerance through recurrent selection (Shearman, 2006), and targeted gene transfer approaches have been explored (Jaglo-Ottosen et al., 1998). An alternative method of freeze protection involves the application of compounds that promote freeze avoidance or tolerance. Products evaluated on tomato (Davis et al., 1990; Moratiel et al., 2011; Perry et al., 1992), pepper (Perry et al., 1992), peach [Prunus persica (Aoun et al., 1993)], grape [Vitis vinifera (Gardea et al., 1993)], and strawberry $[$ Fragaria $\times$ ananassa (Anderson and Whitworth, 1993)] generally provided very limited increases in freeze resistance. FreezePruf is a commercially available product recently marketed by the Liquid Fence Company (Broadheadsville, PA) to improve both freeze avoidance and tolerance. FreezePruf contains polyethylene glycol, potassium silicate (AgSil 25; PQ Corp., Valley Forge, PA), glycerol, silicone polyether surfactant (Silwet L-77; Setre Chemical Co., Memphis, TN), and a bicyclic oxazolidine antidessicant (Wilt-Pruf; Wilt-Pruf Products, Essex, CT) (Franko et al., 2011).

\begin{tabular}{llll}
\hline $\begin{array}{l}\text { Units } \\
\text { To convert U.S. to SI, } \\
\text { multiply by }\end{array}$ & U.S. unit & SI unit & $\begin{array}{l}\text { To convert SI to U.S., } \\
\text { multiply by }\end{array}$ \\
\hline 29.5735 & $\mathrm{fl} \mathrm{oz}$ & $\mathrm{mL}$ & 0.0338 \\
2.54 & inch $(\mathrm{es})$ & $\mathrm{cm}$ & 0.3937 \\
25.4 & inch $(\mathrm{es})$ & $\mathrm{mm}$ & 0.0394 \\
28.3495 & $\mathrm{oz}$ & $\mathrm{g}$ & 0.0353 \\
7.4892 & $\mathrm{oz} / \mathrm{gal}$ & $\mathrm{g} \cdot \mathrm{L}^{-1}$ & 0.1335 \\
$\left({ }^{\circ} \mathrm{F}-32\right) \div 1.8$ & ${ }^{\circ} \mathrm{F}$ & ${ }^{\circ} \mathrm{C}$ & $\left(1.8 \times{ }^{\circ} \mathrm{C}\right)+32$
\end{tabular}


Franko et al. (2011) suggested hypothetical mechanisms of action may include colligative freezing point depression, noncolligative membrane stabilization, stimulation of proline production, cell wall reinforcement, and reduction in water loss from leaves. A report by the developer indicated that up to $5^{\circ} \mathrm{C}$ (equivalent to one U.S. Department of Agriculture plant hardiness zone) protection was provided to flowers, leaves, and fruit (Franko et al., 2011). While the level of protection varied with plant material, a $5{ }^{\circ} \mathrm{C}$ increase in freeze avoidance or tolerance would be biologically and economically significant.

The goal of the present study was to evaluate the protection level provided by FreezePruf using laboratorybased methods involving plants and plant parts from species capable and incapable of low-temperature acclimation. Specific objectives were to determine if FreezePruf 1) lowered the freezing temperature of detached tomato leaves in test tubes in a circulating bath, 2) lowered the freezing temperature of pepper and celosia seedlings in a convection chamber, 3 ) lowered the freezing temperature of postharvest tomato fruit in a convection chamber, and 4 ) increased the freeze tolerance of bermudagrass crowns and stolons.

\section{Materials and methods}

Detached tomato leaves. 'Supersonic' tomato seeds purchased from Harris Seeds (Rochester, NY) were sown in $21 \times 15 \times 4$-inch (length $\times$ width $\times$ height) flats containing a commercial potting mix (BM-1; Berger Peat Moss, St. Modeste, QC, Canada) amended with $0.7 \mathrm{~g} \cdot \mathrm{L}^{-1}$ triple superphosphate, $3.6 \mathrm{~g} \cdot \mathrm{L}^{-1}$ dolomite, $0.6 \mathrm{~g} \cdot \mathrm{L}^{-1}$ Micromax (Scotts, Marysville, $\mathrm{OH}$ ), and $0.6 \mathrm{~g} \cdot \mathrm{L}^{-1}$ potassium nitrate $\left(\mathrm{KNO}_{3}\right)$. Plants were maintained in a controlledenvironment chamber (model LT105; Percival Scientific, Perry, IA), at $($ mean $\pm \mathrm{SD}) 27.1 \pm 0.2 / 22.9 \pm 0.3^{\circ} \mathrm{C}$ temperatures (day/night) with a 14-h photoperiod and a photosynthetic photon flux density at canopy height of $\approx 400 \mu \mathrm{mol} \cdot \mathrm{m}^{-2} \cdot \mathrm{s}^{-1}$. Relative humidity was $47 \% \pm 6 \%$. Plants were watered with soluble fertilizer $(20 \mathrm{~N}-8.6 \mathrm{P}-$ $16.6 \mathrm{~K}$, Peters, Scotts) at $0.7 \mathrm{~g} \cdot \mathrm{L}^{-1}$ as needed based on media color and flat weight. Seedlings were thinned to 20 plants per flat shortly after emergence. Plants were assayed 3 weeks after sowing seeds. For each experiment, 20 plants were sprayed with deionized water (control) or the commercial formulation (ready to use) of FreezePruf $24 \mathrm{~h}$ before low-temperature exposure. Treatments were randomly assigned to flats. The oldest true leaf was detached from each plant with a razor blade and weighed. A thermocouple junction was taped to the petiole before the leaf was placed in a $25 \times$ $150-\mathrm{mm}$ test tube. The terminal 100 $\mathrm{cm}$ of 0.005 -inch-diameter thermocouple wire was placed into the test tube to minimize conduction. A datalogger (model 21X; Campbell Scientific, Logan, UT) recorded temperatures at 60 -s intervals. Twenty test tubes per treatment were covered with plastic caps and placed in a weighted rack. The rack was inserted in a circulating bath (model RM 20; Lauda-Brinkmann, Lauda-Königshofen, Germany) set at $-3.5^{\circ} \mathrm{C}$ and held for $\mathrm{l}$ h. Bath temperature was then lowered $0.5^{\circ} \mathrm{C}$ every 15 min until all of the samples froze. The freezing temperature was recorded as the lowest temperature reached before the heat of fusion was evidenced as an exotherm.

Pepper and celosia seedlings. 'Ace' pepper and 'Kewpie Orange' celosia plants were grown the same as tomato plants except individual 2.5inch square pots were used instead of flats. Pepper seeds were purchased from Stokes Seeds (St. Catherines, ON, Canada) and celosia seeds were purchased from Carolina Seeds (Boone, NC). Supercooling assays were conducted in separate experiments for pepper and celosia. For each experiment, twelve 3 -week-old seedlings were randomly selected and sprayed with deionized water (control) and an additional 12 plants were sprayed with FreezePruf 24 h before low-temperature exposure. A thermocouple junction was taped to the largest leaf before seedlings were placed in a tray that insulated the pots to eliminate the possibility of secondary nucleation from frozen water in the potting medium. The chamber (model CEC23; Rheem Scientific, Asheville, NC) was cooled rapidly to $0{ }^{\circ} \mathrm{C}$ and then cooled at $2{ }^{\circ} \mathrm{C}$ per hour to $-20^{\circ} \mathrm{C}$. Freezing temperatures were recorded based on exotherm analysis.

Tomato Fruit. Cherry tomatoes (cultivar unknown) were purchased from a local supermarket. For each experiment, 20 randomly selected fruit were sprayed with deionized water (control) and an additional 20 fruit were sprayed with FreezePruf $24 \mathrm{~h}$ before low-temperature exposure. Fruit were maintained at ambient laboratory conditions after treatment. A thermocouple junction was taped to the surface of each fruit after weighing. Fruit were placed in a convection chamber on wire racks covered with polyethylene. Chamber temperature was lowered rapidly to $0^{\circ} \mathrm{C}$. After $\mathrm{l} \mathrm{h}$ at $0{ }^{\circ} \mathrm{C}$, chamber temperature was lowered to $-20{ }^{\circ} \mathrm{C}$ at $1^{\circ} \mathrm{C}$ per hour. Freezing temperatures were recorded based on exotherm analysis.

Bermudagrass. 'Riviera' bermudagrass seed was obtained from the breeder (C. Taliaferro). About 20 $\mathrm{mg}$ of bermudagrass seed was planted in each cone-tainer (Ray Leach Conetainer Nursery, Canby, OR) filled with the same potting medium used for pepper, celosia, and tomato plants. Environmental conditions in the growth chamber were the same as for other plants. After 8 weeks of establishment, leaves and stolons were sprayed with deionized water (control) or FreezePruf. Plants were sprayed a second time $7 \mathrm{~d}$ later, $24 \mathrm{~h}$ before low-temperature exposure. Freeze tolerance of stolons and crowns were evaluated separately. Leaves were removed from stolons with a razor blade $\approx 1 \mathrm{~mm}$ from the collar. Three stolon segments with at least two nodes were placed in each test tube containing $3 \mathrm{~mL}$ distilled water. Tubes were chilled in an ice-water bath, and then ice chips were dropped into the tubes to nucleate samples upon further cooling. Weighted racks of test tubes were placed in a circulating bath at $-2{ }^{\circ} \mathrm{C}$. Four tubes each of controls and FreezePruf-treated stolons were removed from the bath after $20 \mathrm{~h}$ and placed in an ice-water bath to thaw slowly. Bath temperature was subsequently lowered to $-3{ }^{\circ} \mathrm{C}$ and additional samples were removed after $\mathrm{l} \mathrm{h}$. The process was repeated for target temperatures from -4 to $-7^{\circ} \mathrm{C}$ with $1{ }^{\circ} \mathrm{C}$ intervals. A set of eight tubes (four control and four treated with cryoprotectant) exposed to $0{ }^{\circ} \mathrm{C}$ was treated identically, except tubes were placed directly in an ice-water bath instead of the circulating lowtemperature bath. After thawing, an additional $17 \mathrm{~mL}$ distilled water was added to each tube and electrical conductivity of the solution was measured after $16 \mathrm{~h}$ on an orbital shaker at $60 \mathrm{rpm}$. Samples were heat-killed by 
placing them in a water bath at $65^{\circ} \mathrm{C}$ for $\mathrm{l} \mathrm{h}$, and then final conductivity measurements were taken after an additional 6-h incubation at $\approx 21{ }^{\circ} \mathrm{C}$. Tissue responses (electrolyte leakage) were expressed as: (initial conductivity/ final conductivity) $\times 100$.

After stolons were sampled, all remaining top growth was removed from the cone-tainers and thermocouples attached to wooden stakes were inserted $2 \mathrm{~cm}$ into the medium. Sample temperatures were recorded with a datalogger at 5-min intervals initially, then at 1-min intervals during the period samples were removed. Crushed ice was placed on the top of each cone-tainer before being placed into a freeze chamber and cooled rapidly to $-2{ }^{\circ} \mathrm{C}$. Samples were held at $-2{ }^{\circ} \mathrm{C}$ for $20 \mathrm{~h}$, then the freeze chamber was programmed to cool linearly at $1{ }^{\circ} \mathrm{C}$ per hour. For each treatment, four randomly selected cone-tainers were removed at each test temperature from -2 to $-7{ }^{\circ} \mathrm{C}\left(1{ }^{\circ} \mathrm{C}\right.$ intervals). Cone-tainers were held overnight at $\approx 4{ }^{\circ} \mathrm{C}$ after removal from the freeze chamber. Controls were treated identically, except they were not placed into the freeze chamber. Following thawing, plants were placed in a growth chamber at $27 / 23{ }^{\circ} \mathrm{C}$ day/night temperatures for a regrowth period of 5 weeks. Regrowth was quantified separately from each cone-tainer by weighing the fresh weight of shoots removed by cutting flush with the top of the cone-tainer.

Separate analyses of variance (ANOVA) were carried out for each series of experiments using the general linear models procedure (SAS version 9.3; SAS Institute, Cary, $\mathrm{NC})$. Experiments were repeated in time (three dates for tomato leaves, tomato fruit, and bermudagrass; five dates for pepper and celosia seedlings) with dates analyzed as blocks with random effects. Weight was a covariate (Anderson, 1988) in experiments with tomato leaves and fruit. Separate ANOVA were carried out for the two bermudagrass assays with electrolyte leakage data arcsine transformed before analysis. An alpha level of 0.05 was used to test for significance.

\section{Results and discussion}

Detached tomato Leaves. No difference was observed in mean freezing temperatures of detached tomato leaves sprayed with water $\left(-7.3^{\circ} \mathrm{C}\right)$ or FreezePruf $\left(-7.6^{\circ} \mathrm{C}\right)$ (Table 1). The observed freezing temperatures were similar to previous studies examining small tomato plants and plant parts without detectable levels of extrinsic ice nucleators (Anderson and Ashworth, 1985). A recent study by Moratiel et al. (2011) examined freezing behavior of tomato seedlings treated with several cryoprotectants. The authors examined the effects of dimethyl sulfoxide, proline, polyvinylpyrrolidone, a mixture of amino acids, and a solution containing glycerol and vitamin E. The only treatment that increased the survival percentage after exposure to $-4^{\circ} \mathrm{C}$ for $\mathrm{l} \mathrm{h}$ was glycerol plus vitamin E. It was interesting to note that protection was not strictly a colligative effect since $0.7 \mathrm{M}$ glycerol was optimum, but higher or lower concentrations had survival percentages that were not different from the control. Although Moratiel et al. (2011) did not examine FreezePruf, glycerol ( $5 \mathrm{~mm})$ is one of the components (Franko et al., 2011).

Pepper and celosia seedlings. No difference was observed in mean freezing temperatures of pepper seedlings sprayed with water $\left(-7.2^{\circ} \mathrm{C}\right)$ or FreezePruf $\left(-7.3{ }^{\circ} \mathrm{C}\right)$ (Table 1$)$. Similarly, supercooling of celosia seedlings was not enhanced by FreezePruf (Table 1). Although relatively few experiments focusing on supercooling of ornamental plants have been published, a previous study reported median freezing temperatures of $\approx-6$ to $-7^{\circ} \mathrm{C}$ for a variety of bedding plants (Anderson et al., 1981).

Tomato Fruit. Franko et al. (2011) indicated FreezePruf increased the percentage of viable tomato fruit by $\approx 50 \%$ compared with controls exposed to $-3.9^{\circ} \mathrm{C}$ for 2 to $3.5 \mathrm{~h}$. Based on that report, a preliminary experiment was conducted to determine whether the supercooling duration of tomato fruit held at $-3.9^{\circ} \mathrm{C}$ was increased by FreezePruf. However, only one out of 40 fruit exhibited an exotherm during $24 \mathrm{~h}$ at $-3.9^{\circ} \mathrm{C}$. A subsequent series of experiments determining the freezing temperatures of fruit cooled continuously at $-1{ }^{\circ} \mathrm{C}$ per hour indicated a median freezing temperature of $-11.7^{\circ} \mathrm{C}$. Application of FreezePruf did not lower the freezing temperature of tomato fruit relative to controls sprayed with water (Table 1).

Bermudagrass. FreezePruf had no effect on freeze tolerance of bermudagrass. Tissues exhibited little or no tolerance of freezing based on regrowth from crowns and electrolyte leakage from stolons (Table 2). Although it has been shown previously that 'Riviera' bermudagrass can cold acclimate to $-7.7^{\circ} \mathrm{C}$ (Anderson et al., 2007), no evidence was observed of stimulated signal transduction pathways leading to acclimation of bermudagrass treated with FreezePruf. Since crowns were not directly treated with FreezePruf, acclimation would have necessitated translocation of the cryoprotectant or a hardiness promoter. Stolons, which were directly treated with FreezePruf, did not exhibit increased freeze tolerance compared with controls sprayed with water. In addition to treatment $24 \mathrm{~h}$ before assay (Franko et al., 2011), bermudagrasses in the present report were also treated 1 week before lowtemperature exposure to allow for translocation and promotion of acclimation. Although no freeze protection

Table 1. Freezing temperatures (least squares means) of tomato leaves, pepper seedlings, celosia seedlings, and tomato fruit sprayed with water (control) or FreezePruf (Liquid Fence Company, Broadheadsville, PA) 24 h before exposure to low temperatures. FreezePruf contains polyethylene glycol, potassium silicate, glycerol, silicone polyether surfactant, and a bicyclic oxazolidine antidessicant. Experiments were repeated in time with the cumulative number of samples per treatment equal to 60 .

\begin{tabular}{lccr}
\hline & \multicolumn{2}{c}{ Freezing temp $\left({ }^{\circ} \mathbf{C}\right)^{\mathbf{z}}$} & $P>\mathbf{F}^{\mathbf{y}}$ \\
\cline { 2 - 4 } Plant sample & Control & FreezePruf & 0.21 \\
\hline Tomato leaves & -7.3 & -7.6 & 0.71 \\
Pepper seedlings & -7.2 & -7.3 & 0.28 \\
Celosia seedlings & -6.1 & -6.2 & 0.14 \\
Tomato fruit & -11.6 & -10.9 \\
\hline${ }^{z}\left(1.8 \times{ }^{\circ} \mathrm{C}\right)+32={ }^{\circ} \mathrm{F}$. & \\
vPlant samples were analyzed separately with significance probability values $(P>\mathrm{F})$ reported from an analysis of \\
variance. Treatment differences were tested at an alpha level of 0.05.
\end{tabular}


Table 2. Percentage electrolyte leakage from 'Riviera' bermudagrass stolons and regrowth weight (fresh weight) from crowns following exposure to temperatures from 0 to $-7^{\circ} \mathrm{C}\left(32.0\right.$ to $\left.19.4^{\circ} \mathrm{F}\right)$. Stolons were exposed to low temperatures in test tubes in a circulating bath and crowns in cone-tainers (Ray Leach Cone-tainer Nursery, Canby, OR) were exposed in a convection chamber. FreezePruf (Liquid Fence Co., Broadheadsville, PA) contains polyethylene glycol, potassium silicate, glycerol, silicone polyether surfactant, and a bicyclic oxazolidine antidessicant.

\begin{tabular}{|c|c|c|c|c|}
\hline \multirow[b]{2}{*}{ Freezing temp $\left({ }^{\circ} \mathrm{C}\right)^{\mathrm{z}}$} & \multicolumn{2}{|c|}{$\begin{array}{l}\text { Stolon electrolyte leakage } \\
{[\text { mean } \pm \operatorname{SE}(\%)]^{\mathrm{y}}}\end{array}$} & \multicolumn{2}{|c|}{$\begin{array}{l}\text { Crown regrowth } \\
{[\text { mean } \pm S E(g)]^{\mathrm{y}}}\end{array}$} \\
\hline & Control & FreezePruf & Control & FreezePruf \\
\hline 0 & $25 \pm 4$ & $21 \pm 3$ & $18.81 \pm 1.11$ & $16.13 \pm 0.68$ \\
\hline-2 & $74 \pm 3$ & $67 \pm 4$ & $1.70 \pm 0.43$ & $2.67 \pm 0.94$ \\
\hline-3 & $78 \pm 3$ & $79 \pm 2$ & $0.13 \pm 0.08$ & $0.04 \pm 0.03$ \\
\hline-4 & $91 \pm 1$ & $89 \pm 1$ & 0 & 0 \\
\hline-5 & $91 \pm 1$ & $92 \pm 1$ & 0 & 0 \\
\hline-6 & $95 \pm 1$ & $93 \pm 1$ & 0 & 0 \\
\hline-7 & $96 \pm 1$ & $94 \pm 1$ & 0 & 0 \\
\hline Date & \multicolumn{2}{|c|}{$\mathrm{NS}^{\mathrm{x}}$} & \multicolumn{2}{|c|}{ NS } \\
\hline Treatment & \multicolumn{2}{|c|}{ NS } & \multicolumn{2}{|c|}{ NS } \\
\hline Temperature & \multicolumn{2}{|c|}{$* * *$} & \multicolumn{2}{|c|}{$* * *$} \\
\hline
\end{tabular}

${ }^{2}\left(1.8 \times{ }^{\circ} \mathrm{C}\right)+32={ }^{\circ} \mathrm{F}$.

'Electrolyte leakage and regrowth values represent means $\pm \mathrm{SE}$ from $n=12$. Each experiment was conducted on three dates with four subsamples per treatment combination per date; $1 \mathrm{~g}=0.0353 \mathrm{oz}$.

${ }^{{ }^{N} \mathrm{NS},}{ }^{*},{ }^{* *},{ }^{* *}=$ not significant, significant at $P \leq 0.05$, significant at $\leq 0.01$, and significant at $P \leq 0.001$, respectively. Separate analyses of variance were conducted for electrolyte leakage and regrowth data.

benefit was observed in bermudagrass not exposed to acclimating temperatures, it is possible that FreezePruf could augment acclimation in conjunction with low temperature-induced tolerance.

\section{Conclusions}

FreezePruf did not lower the freezing temperature of detached tomato leaves, pepper seedlings, celosia seedlings, or postharvest tomato fruit and did not increase the freeze tolerance of bermudagrass crowns or stolons. Studies were conducted in a convection chamber and in test tubes immersed in a circulating bath. There may be other experimental protocols that indicate greater freeze resistance following FreezePruf application. Differences in effectiveness of FreezePruf compared with a previous report (Franko et al., 2011) could also be due to differences in plant materials. Although most of the plant materials differed between studies, the reports have the common comparator of tomato fruit. Although the tomato cultivars were unknown (and likely different), a previous report (Anderson, 1988) found no significant differences in supercooling of six tomato cultivars. The diverse choice of plant material in the present study was based primarily on claims that FreezePruf was effective for frost protection of fruits, flowers, and foliage of ornamental, fruit, and vegetable plants (Franko et al., 2011; Liquid Fence Co., 2011).

\section{Literature cited}

Anderson, J.A. 1988. Ice-nucleation activity of seedlings of six tomato cultivars. HortScience 23:1044-1045.

Anderson, J.A. and E.N. Ashworth. 1985. Ice nucleation in tomato plants. J. Amer. Soc. Hort. Sci. 110:291-296.

Anderson, J.A., D.W. Buchanan, and D.L. Ingram. 1981. The role of Pseudomonas syringae, an ice nucleation active bacteria, in frost damage of tender annual plants. Proc. Florida State Hort. Soc. 94:72-74.

Anderson, J.A., C.M. Taliaferro, and Y. Wu. 2007. Freeze tolerance of seed- and vegetatively-propagated bermudagrasses compared with standard cultivars. Appl. Turfgrass Sci. Online doi:10.1094/ATS2007-0508-01-RS.

Anderson, J.A. and J. Whitworth. 1993. Supercooling strawberry plants inoculated with ice-nucleation active bacteria and treated with Frostgard. HortScience 28:828-830.

Aoun, M.F., K.B. Perry, W.H. Swallow, D.J. Werner, and M.L. Parker. 1993. Antitranspirant and cryoprotectant do not prevent peach freezing injury. HortScience 28:343.

Ashworth, E.N. and G.A. Davis. 1984. Ice nucleation within peach trees. J. Amer. Soc. Hort. Sci. 109:198-201.
Cary, J.W. and H.F. Mayland. 1970. Factors influencing freezing of supercooled water in tender plants. Agron. J. 62:715-719.

Davis, T.D., J.E. Ells, and R.H. Walser. 1990. Emergence, growth, and freezing tolerance of tomato seedlings grown from uniconazole-treated seed. HortScience 25:312-313.

Franko, D.A., K.G. Wilson, Q.Q. Li, and M.A. Equiza. 2011. A topical spray to enhance plant resistance to cold injury and mortality. HortTechnology 21:109-118.

Gardea, A.A., P.B. Lombard, C.H. Crisosto, L.W. Moore, L.H. Fuchigami, and L.V. Gusta. 1993. Evaluation of Frostgard as an antifreeze, inhibitor of ice nucleators, and cryoprotectant on pinot noir leaf tissue. Amer. J. Enol. Viticult. 44:232-235.

Gusta, L.V., M.E. Wisniewski, and R.G. Trischuk. 2009. Patterns of freezing in plants: The influence of species, environment and experiential procedures, p. 214 225. In: L. Gusta, M. Wisniewski, and K. Tanino (eds.). Plant cold hardiness: From the laboratory to the field. CAB Intl., Wallingford, UK.

Jaglo-Ottosen, K.R., S.J. Gilmour, D.G. Zarka, O. Shabenberger, and M.F. Thomashow. 1998. Arabidopsis CBFI overexpression induces $C O R$ genes and enhances freezing tolerance. Science 280:104-106.

Kuwabara, C., J. Kasuga, D. Wang, Y. Fukushi, K. Arakawa, T. Koyama, T. Inada, and S. Fujikawa. 2011. Change of supercooling capability in solutions containing different kinds of ice nucleators by flavonol glycosides from deep supercooling xylem parenchyma cells in trees. Cryobiology 63:157-163.

Levitt, J. 1980. Responses of plants to environmental stresses. Vol. 1. Chilling, freezing, and high temperature stresses. 2nd ed. Academic Press, New York.

Lindow, S.E. 1983. The role of bacterial ice nucleation in frost injury to plants. Annu. Rev. Phytopathol. 21:363-384.

Liquid Fence Co. 2011. FreezePruf product label. Liquid Fence Co., Broadheadsville, PA.

Minami, A., Y. Kawamura, T. Yamazaki, A. Furuto, and M. Uemura. 2009. Plasma membrane and plant freezing tolerance: Possible involvement of plasma membrane microdomains in cold acclimation, p. 62-71. In: L. Gusta, M. Wisniewski, and K. Tanino (eds.). Plant cold hardiness: From the laboratory to the field. $\mathrm{CAB}$ International, Wallingford, UK. 


\section{Technology and Product Reports}

Moratiel, R., J.M. Durán, and R.L. Snyder. 2011. Freezing resistance in tomato (Lycopersicum esculentum Mill.) using potential cryoprotectors. Eur. J. Hort. Sci. 76:12-17.

Perry, K.B., A.R. Bonanno, and D.W. Monks. 1992. Two putative cryoprotectants do not provide frost and freeze protection in tomato and pepper. HortScience 27:26-27.

Pouleur, S., C. Richard, J.G. Martin, and H. Antoun. 1992. Ice nucleation activity in Fusarium acuminatum and Fusarium avenaceum. Appl. Environ. Microbiol. 58:2960-2964.

Proebsting, E.L. and D.C. Gross. 1988. Field evaluations of frost injury to deciduous fruit trees as influenced by ice nucleation-active Pseudomonas syringae. J. Amer. Soc. Hort. Sci. 103:57-61.

Shearman, R.C. 2006. Fifty years of splendor in the grass. Crop Sci. 46:2218-2229.
Stockinger, E.J. 2009. Winter hardiness and the $C B F$ genes in the Triticeae, $\mathrm{p}$. 119-130. In: L. Gusta, M. Wisniewski, and K. Tanino (eds.). Plant cold hardiness: From the laboratory to the field. CAB International, Wallingford, UK.

Yelonosky, G. 1983. Ice nucleation active (INA) agents in freezing of young citrus trees. J. Amer. Soc. Hort. Sci. 108:10301034. 